\title{
Hubungan Pola Asuh Ibu dengan Status Gizi Balita di Wilayah Kerja Puskesmas Belimbing Kota Padang
}

\author{
Tiara Dwi Pratiwi ${ }^{1}$, Masrul $^{2}$, Eti Yerizel $^{3}$
}

\begin{abstract}
Abstrak
Status gizi merupakan salah satu indikator kesehatan anak. Masa lima tahun (masa balita) adalah periode penting dimana anak membutuhkan kecukupan gizi untuk menunjang pertumbuhan fisiknya. Anak bergantung pada ibu yang berperan dalam pengasuhan dan perawatan anak. Tujuan penelitian ini adalah menentukan hubungan pola asuh ibu dengan status gizi balita di wilayah kerja Puskesmas Belimbing. Telah dilakukan penelitian dengan desain cross-sectional dengan sampel sebanyak 163 ibu dengan 163 anak berumur 12-60 bulan. Ibu sebagai responden, diwawancarai langsung dengan menggunakan kuesioner. Status gizi balita diukur dengan indikator berat badan/tinggi badan dan diinterpretasikan berdasarkan klasifikasi status gizi WHO. Hasil penelitian menunjukkan bahwa $84,7 \%$ balita memiliki status gizi normal dan $15,3 \%$ balita memiliki status gizi kurang. Pola asuh berdasarkan pola asuh makan terbanyak pada kategori sedang yaitu $40,5 \%$, berdasarkan pola asuh kesehatan terbanyak pada kategori baik sebanyak $44,8 \%$ dan pola asuh psikososial terbanyak pada kategori sedang sebanyak $78,5 \%$. Terdapat hubungan yang signifikan antara pola asuh makan dan pola asuh kesehatan dengan status gizi $(p=0,014 ; p=0,006)$. Pola asuh psikososial tidak terdapat adanya hubungan signifikan dengan status gizi $(p=0,842)$. Kesimpulan studi ini menyarankan kepada ibu-ibu agar memperhatikan asupan makan serta perawatan kesehatan anak. Ibu juga seharusnya membawa anak secara rutin ke posyandu atau pelayanan kesehatan terdekat.
\end{abstract}

Kata kunci: pola asuh, status gizi, balita

\begin{abstract}
Nutritional status is one of child's health indicator. The first five year of children life is the important period whereby child needs proper nutrition to support the growth. In order to fulfill this, as a caregiver for the children, every mother has an important role. The objective of this study was to determine the association care practices to nutritional status in children. This study was cross sectional on 163 mothers from 163 children whose age were 12-60 months old. Care practices was measured by interviewed mother by using questionnaire and nutritional status was measured by using body weight/body height according to WHO growth chart. The study showed that $84,7 \%$ children were normal nutritional status and $15,3 \%$ children were underweight. The study also found that $40,5 \%$ children with moderate care for feeding, 44,8\% with good care for health and $78,5 \%$ with moderate care for psychosocial. There was significant association between care for nutrition and care for health with child nutritional status $(p=0,014 ; p=0,006)$ and there was no significant association between care for psychosocial with child nutritional status $(p=0,842)$. The conclusion suggest the mothers have to pay attention with food intake and child health care. Mothers should take their children regularly to public health center.
\end{abstract}

Keywords: care practices, nutritional status, children

Affiliasi penulis: 1. Prodi Profesi Dokter FK UNAND (Fakultas Kedokteran Universitas Andalas Padang), 2. Bagian IImu Gizi FK UNAND, 3. Bagian IImu Biokimia FK UNAND

Korespondensi: Tiara Dwi Pratiwi, Email: tdwipratiwi@gmail.com Telp: 085287216892

\section{PENDAHULUAN}

Kemajuan suatu negara dipengaruhi oleh kualitas sumber daya manusia (SDM) yang dimilikinya. Salah satu kriteria SDM yang berkualitas dapat dilihat 
dari derajat kesehatan. Derajat kesehatan merupakan pencerminan kesehatan perorangan, kelompok, maupun masyarakat yang digambarkan dengan usia harapan hidup, mortalitas, morbiditas dan status gizi masyarakat. $^{1}$

Sehat dapat mencakup pengertian yang sangat luas, selain bebas dari penyakit tetapi juga tercapainya keadaan kesejahteraan baik fisik, sosial dan mental. ${ }^{2}$ Masalah kesehatan anak masih merupakan masalah nasional yang perlu mendapat prioritas utama karena sangat menentukan kualitas sumber daya manusia pada generasi mendatang. ${ }^{1}$

Anak yang sehat merupakan dambaan bagi orang tua yang harus memperhatikan, mengawasi dan merawat anak khususnya pertumbuhan dan perkembangannya. Masa lima tahun (masa balita) adalah periode penting dalam tumbuh kembang anak dan merupakan masa yang akan menentukan pembentukan fisik, psikis dan intelegensinya. $^{3}$

Keadaan gizi anak dipengaruhi oleh berbagai faktor, yang dibedakan menjadi sebab yang langsung dan tidak langsung. Sebab langsung yaitu kecukupan makanan dan keadaan kesehatan anak. Sebab tak langsung yaitu ketahanan makanan keluarga, asuhan bagi ibu dan anak, serta sanitasi lingkungan. ${ }^{4}$

Kekurangan gizi merupakan salah satu masalah utama pada balita. WHO melaporkan pada tahun 2003 sampai 2008, 23\% balita di dunia mengalami gizi kurang $(\mathrm{BB} / \mathrm{U}<2 \mathrm{SD})$ dan $10 \%$ gizi buruk $(B B / U<3$ SD). Yaman merupakan negara dengan tingkat gizi kurang balita tertinggi yaitu $43 \%$. Di Indonesia, prevalensi gizi buruk menurut BB/U pada tahun 2010 adalah 4,9\% dan gizi kurang 13\%. Data menurut provinsi di Indonesia tahun 2010 yang tertinggi adalah provinsi Gorontalo sebesar 11,2\%. Di Sumatera Barat sebesar 2,8\%. ${ }^{5}$ Prevalensi gizi kurang kota Padang tahun 2011 sebsesar 0,10\% dengan angka tertinggi adalah kecamatan Kuranji di Puskesmas Belimbing sebesar 0,29\%. ${ }^{2}$

Pada tahap dasar, kebutuhan seorang anak adalah pangan. Ini merupakan unsur utama untuk pertumbuhan anak, agar anak dapat tumbuh dan berkembang sesuai dengan kemampuan genetiknya. kebutuhan dasar anak untuk tumbuh dapat digolongkan menjadi 3 , yaitu asuh, asih, dan asah. ${ }^{4}$
Pertumbuhan fisik sering dijadikan indikator dalam mengukur status gizi baik individu, maupun populasi. ${ }^{6}$ Orangtua perlu menaruh perhatian pada aspek pertumbuhan anak bila ingin mengetahui keadaan gizi mereka.

Peranan ibu sangat berpengaruh dalam keadaan gizi anak. Pola asuh memegang peranan penting dalam terjadinya gangguan pertumbuhan pada anak. Engle et al menekankan bahwa terdapat tiga komponen penting (makanan, kesehatan- rangsangan psikososial) merupakan faktor yang berperan dalam petumbuhan anak yang optimal. ${ }^{7}$

Penelitian yang dilakukan oleh Sanjaya di Jawa Barat mengenai positive deviance (penyimpangan positif) status gizi balita. ${ }^{8}$ Masithah et al menyebutkan keluarga yang memiliki faktor pengasuhan balita yang baik, akan mampu mengoptimalkan kualitas status gizi balita. $^{9}$ ibu memiliki peranan penting dalam pengasuhan anak. ${ }^{10}$

Status gizi anak merupakan parameter tumbuh kembang anak. ${ }^{11}$ Asuhan ibu terhadap anak mempengaruhi tumbuh kembang anak melalui kecukupan makanan dan keadaan kesehatan. ${ }^{4}$ Berdasarkan hal di atas maka perlu diteliti mengenai hubungan pola asuh dengan status gizi pada balita di wilayah kerja Puskesmas Belimbing Kecamatan Kuranji Kota Padang.

\section{METODE}

Penelitian dilakukan di wilayah kerja Puskesmas Belimbing kota Padang dengan desain cross-sectional. Sampel dalam penelitian ini sebanyak 163 ibu. Metode pengambilan sampel adalah stratified random sampling. Pola asuh makan dan kesehatan diukur dengan wawancara menggunakan kuesioner, sedangkan pola asuh psikososial diukur dengan menggunakan instrumen HOME (Home Observation for Measurement of The Environment). ${ }^{12,13}$ Status gizi balita diukur dengan indikator berat badan/tinggi badan dan diinterpretasikan berdasarkan klasifikasi status gizi dari WHO. Untuk melihat hubungan pola asuh dengan status gizi balita dilakukan uji statistik chi-square. Probabilitas (p) lebih kecil daripada $\alpha$ $(p<0,05)$ berarti ada hubungan yang signifikan antara pola asuh dengan status gizi balita. 


\section{HASIL DAN PEMBAHASAN}

\section{Status Gizi Balita}

Tabel 1. Distribusi status gizi balita berdasarkan indeks BB/TB di wilayah kerja Puskesmas Belimbing tahun 2013

\begin{tabular}{lll}
\hline Status Gizi & Frekuensi & Persentase(\%) \\
\hline Kurang & 25 & 15,3 \\
Normal & 138 & 84,7 \\
\hline Jumlah & $\mathbf{1 6 3}$ & $\mathbf{1 0 0}$
\end{tabular}

Pada Tabel 1 disimpulkan bahwa masih tingginya angka balita dengan status gizi kurang sebanyak 15,3\%. Pada penelitian ini tidak ditemukan balita dengan status gizi sangat kurang atau lebih. Hasil ini lebih besar dibanding dengan persentase balita dengan status gizi kurang di Indonesia dan Sumatra Barat sebesar $7,3 \%$ dan $4,2 \%{ }^{14}$ Hal ini menunjukkan bahwa masih tingginya angka balita dengan status gizi kurang di wilayah kerja puskesmas Belimbing. Mengapa balita dengan status gizi kurang masih banyak di wilayah tersebut? Hal ini bisa saja disebabkan oleh berbagai macam faktor. Pertama, faktor ekonomi. Menurut Adisasmito, proporsi anak dengan gizi kurang berbanding terbalik dengan pendapatan. ${ }^{15}$ Dalam penelitian ini kepala keluarga, yaitu ayah, banyak yang bekerja sebagai wiraswasta sebanyak $45,4 \%$ serta buruh sebesar $21,5 \%$. Selain itu, 90,2\% responden ialah ibu rumah tangga sehingga pendapatan keluarga hanya bergantung pada kepala keluarga. Kemudian faktor berikutnya,masih banyaknya pola asuh makan yang rendah sebesar 31,9\%. Kecukupan asupan nutrisi anak berperan dalam kebutuhan gizi anak. ${ }^{11}$ Kemudian pola asuh kesehatan masih banyak yang rendah sebesar 16,0\%. Angka ini lebih tinggi dibandingkan dengan Masithah et al dalam penelitiannya terhadap balita di desa Mulyaharja, Bogor, menemukan pola asuh kesehatan dengan kategori rendah sebesar $1,5 \%{ }^{8}$ Anak yang mengalami penyakit tentu akan terhambat penyerapan nutrisinya sehingga dapat berpengaruh pada status gizi anak. ${ }^{16}$

Status gizi merupakan indikator penting untuk kesehatan anak. Hal ini disebabkan karena status gizi merupakan salah satu faktor resiko untuk terjadinya kesakitan dan kematian. Status gizi yang baik pada anak akan berkontribusi terhadap kesehatannya dan juga kemampuan dalam proses pemulihan dari suatu penyakit. ${ }^{16}$

\section{Hubungan Pola Asuh Makan dengan Status Gizi Balita}

Tabel 2. Hubungan pola asuh makan dengan status gizi balita di wilayah kerja Puskesmas Belimbing tahun 2013

\begin{tabular}{|c|c|c|c|c|c|c|c|}
\hline \multirow{3}{*}{$\begin{array}{c}\text { Status } \\
\text { Gizi }\end{array}$} & \multicolumn{6}{|c|}{ Pola asuh makan } & \multirow{3}{*}{$\mathbf{p}$} \\
\hline & \multicolumn{2}{|c|}{ rendah } & \multicolumn{2}{|c|}{ sedang } & \multicolumn{2}{|c|}{ baik } & \\
\hline & $\mathbf{n}$ & $\%$ & $\mathbf{n}$ & $\%$ & $\mathbf{n}$ & $\%$ & \\
\hline Kurang & 14 & $56,0 \%$ & 8 & $32,0 \%$ & 3 & $12,0 \%$ & \\
\hline Normal & 38 & $27,5 \%$ & 58 & $42,0 \%$ & 42 & $30,4 \%$ & $\mathbf{0 , 0 1 4}$ \\
\hline Jumlah & 52 & $31,9 \%$ & 66 & $40,5 \%$ & 45 & $27,6 \%$ & \\
\hline
\end{tabular}

Berdasarkan Tabel 2 dapat disimpulkan bahwa persentase balita dengan status gizi kurang paling banyak pada balita dengan pola asuh makan rendah sebanyak 56,0\% dibandingkan dengan balita dengan status gizi normal paling banyak dengan kategori pola asuh makan sedang sebanyak 42,0\%. Hasil uji statistic chi-square didapatkan nilai $\mathrm{p}=0,014$. Berdasarkan hasil tersebut dapat disimpulkan bahwa terdapat hubungan yang bermakna antara pola asuh makan dengan status gizi balita di wilayah kerja puskesmas Belimbing.

Pemberian makan yang baik sangat penting untuk asupan nutrisi, tidak hanya dari segi apa yang dimakan anak, tapi sikap ibu juga berperan. Misalnya saja adanya kehadiran ibu untuk mengawasi anak makan. Dengan pemberian makan yang baik maka akan menunjang status gizi anak. ${ }^{17}$

Sulistijani mengungkapkan bahwa seiring dengan pertambahan usia anak maka ragam makanan yang diberikan harus bergizi lengkap dan seimbang sehingga penting untuk menunjang pertumbuhan dan perkembangan anak. ${ }^{3}$

Pengetahuan ibu mengenai asupan nutrisi anak dan cara pengasuhan terkait dengan pendidikan ibu, serta kebiasaan di keluarga dan masyarakat. Wawasan ini juga dapat diperoleh melalui petugas kesehatan setempat saat berkunjung ke posyandu dan tempat pelayanan kesehatan terdekat. 
Hasil ini sesuai dengan penelitian Masithah et al yang menyatakan bahwa pemberian pola asuh makan yang memadai berhubungan dengan baiknya kualitas konsumsi makanan anak, yang pada akhirnya akan mempengaruhi kualitas status gizi anak tersebut. $^{9}$ Penelitian Nti dan Lartey di Ghana menunjukkan bahwa pola asuh makan yang baik berpengaruh terhadap status gizi anak usia 6-12 bulan yang diukur dengan indeks BB/U dan TB/U. ${ }^{18}$

\section{Hubungan Pola Asuh Kesehatan dengan Status Gizi Balita}

Tabel 3. Hubungan pola asuh kesehatan dengan status gizi balita di wilayah kerja Puskesmas Belimbing tahun 2013

\begin{tabular}{cccccccc}
\hline Status & \multicolumn{6}{c}{ Pola asuh kesehatan } & \multirow{2}{*}{ p } \\
\cline { 2 - 6 } & \multicolumn{2}{c}{ rendah } & \multicolumn{2}{c}{ sedang } & \multicolumn{2}{c}{ baik } & \\
& $\mathbf{n}$ & $\%$ & $\mathbf{n}$ & $\%$ & $\mathbf{n}$ & $\%$ & \\
\hline Kurang & 5 & $20,0 \%$ & 16 & $64,0 \%$ & 4 & $16,0 \%$ & \\
Normal & 21 & $15,2 \%$ & 48 & $34,8 \%$ & 69 & $50,0 \%$ & 0,006 \\
\hline Jumlah & 26 & $16,0 \%$ & 64 & $39,3 \%$ & 73 & $44,8 \%$ & \\
\hline
\end{tabular}

Pada Tabel 3 dapat disimpulkan bahwa balita dengan status gizi kurang paling banyak dengan pola asuh kesehatan sedang sebanyak 64,0\%. Pada balita dengan status gizi normal paling banyak dengan pola asuh kesehatan baik sebanyak 50,0\%. Hasil uji statistik dengan menggunakan chi-square didapatkan nilai $p=0,006$. Berdasarkan hasil tersebut dapat disimpulkan bahwa terdapat hubungan yang bermakna antara pola asuh kesehatan dengan status gizi balita di wilayah kerja puskesmas Belimbing.

Anak balita merupakan kelompok rawan gizi dan kesehatan. Penyakit yang paling sering diderita anak ialah infeksi. Anak yang mengalami sakit akan terganggu penyerapan nutrisinya sehingga mempengaruhi status gizi anak. ${ }^{4}$

Pola asuh kesehatan yang diukur merupakan upaya preventif seperti pemberian imunisasi maupun pola asuh ketika anak dalam keadaan sakit. ${ }^{7}$

Hasil penelitian ini sesuai dengan Lubis (2008) pada balita di wilayah kerja Puskesmas Pantai Cermin Kecamatan Tanjung Pura Langkat Sumatra Utara yang menyebutkan bahwa terdapat hubungan yang signifikan antara pola asuh kesehatan dengan status gizi balita. ${ }^{19}$ Penelitian yang dilakukan Yulia et al pada anak balita yang merupakan keluarga pemetik teh di Pangalengan menyebutkan bahwa pola asuh kesehatan berperan terhadap status gizi anak. ${ }^{20}$

\section{Hubungan Pola Asuh Psikososial dengan Status Gizi Balita}

Tabel 4. Hubungan pola asuh psikososial dengan status gizi balita di wilayah kerja Puskesmas Belimbing tahun 2013

\begin{tabular}{cccccccc}
\hline Status & \multicolumn{6}{c}{ Pola asuh psikososial } & \\
\cline { 2 - 7 } Gizi & \multicolumn{2}{c}{ Rendah } & \multicolumn{2}{c}{ Sedang } & Baik & p \\
& $\mathbf{n}$ & $\%$ & n & $\%$ & n & $\%$ & \\
\hline Kurang & 6 & $24,0 \%$ & 19 & $76,0 \%$ & 0 & $0 \%$ & 0,842 \\
Normal & 28 & $20,3 \%$ & 109 & $79,0 \%$ & 1 & $0,6 \%$ & \\
\hline Jumlah & 34 & $20,9 \%$ & 128 & $78,5 \%$ & 1 & $0,6 \%$ & \\
\hline
\end{tabular}

Pada Tabel 4 dapat disimpulkan bahwa balita dengan status gizi kurang paling banyak dengan pola asuh psikososial sedang sebanyak $76,0 \%$. Sedangkan balita dengan status gizi normal juga paling banyak dengan pola asuh psikososial sedang sebanyak $79,0 \%$. Hasil uji statistik dengan chi-square didapatkan nilai $p=0,842$. Berdasarkan hasil tersebut dapat disimpulkan bahwa tidak terdapat hubungan bermakna antara pola asuh psikososial dengan status gizi balita di wilayah kerja Puskesmas Belimbing.

Penelitian yang dilakukan oleh Lubis pada anak balita di wilayah kerja puskesmas Pantai Cermin kecamatan Tanjung Pura, Langkat, Sumatra Utara juga menunjukkan hasil yang sama yaitu tidak terdapat hubungan yang bermakna antara pola asuh psikososial dengan status gizi balita. ${ }^{19}$

Hal ini bertentangan dengan pendapat Engle (1997), rangsangan psikososial yang baik berkaitan dengan kesehatan anak sehingga secara tidak langsung dapat mempengaruhi status gizi anak. ${ }^{7}$ Kualitas pola asuh psikososial ini sendiri tergantung dari keadaan keluarga, masyarakat serta lingkungan. ${ }^{14}$ Namun status gizi tidak semata-mata dipengaruhi oleh pola asuh psikososial. Ada banyak faktor lain yang mempengaruhi status gizi balita seperti faktor ekonomi, pendidikan keluarga, dan lain-lain. ${ }^{9}$ 


\section{KESIMPULAN}

Terdapat hubungan yang signifikan antara pola asuh makan dan pola asuh kesehatan dengan status gizi, tetapi Pola asuh psikososial tidak terdapat adanya hubungan signifikan dengan status gizi.

\section{UCAPAN TERIMA KASIH}

Terimakasih kepada warga di wilayah kerja Puskesmas Belimbing yang telah bersedia menjadi responden dan berbagi pengalaman serta pengetahuan demi kelancaran penelitian ini.

\section{DAFTAR PUSTAKA}

1. Dinas Kesehatan Kota Padang. Profil kesehatan tahun 2007. Padang; 2007.

2. Dinas Kesehatan Kota Padang. Laporan tahunan tahun 2010. Padang; 2011.

3. Sulistijani AD. Menjaga kesehatan bayi dan balita. Jakarta: Puspa Swara; 2001.

4. Soetjiningsih. Tumbuh kembang anak. Jakarta: EGC; 1995.

5. Kementerian Kesehatan Republik Indonesia. Riset kesehatan dasar (Riskesdas). Kemenkes RI; 2010.

6. Khomsan A. Pangan dan gizi untuk kesehatan. Jakarta: PT. Grafindo Persada; 2002.

7. Engle PL, Menon P, Hadad L. Care and nutrition: concepts and measurements. Washington DC: FCND Discussion Paper No. 18. 1997.

8. Sanjaya. Penyimpangan positif (positive deviance) status gizi anak balita dan faktor-faktor yang berpengaruh. Bogor: Puslitbang Gizi; 2002.

9. Mashitah T, Soekirman, Martianto D. Hubungan pola asuh makan dan kesehatan dengan status gizi anak batita di Desa Mulya Harja. Media Gizi dan Keluarga. 2005; 29(2):29-39.

10. Pola Asuh Tentukan Status Gizi Anak. 2010 Des (diunduh 21 Februari 2012). Tersedia dari: URL: HYPERLINK http://www.go4healthylife.com/ articles/3262/1/Pola-Asuh-Tentukan-Status-GiziAnak/Page1.html
11. Supariasa, Bakri B, Fajar I. Penilaian status gizi. Jakarta: EGC; 2001.

12. Caldwell BM, Bradley RH. Home inventory and administration manual. University of Arkansas for Medical Science and University of Arkansas at Little Rock; 2001.

13. Masrul. Kajian peranan sumber daya pengasuhan terhadap tumbuh kembang bayi usia 6-12 bulan pada keluarga etnik Minangkabau di pedesaan Propinsi Sumatera Barat (disertasi). Surabaya: Universitas Airlangga; 2005.

14. Februhartanty J, Usfar AA, Dianawati E, Fransisca DO, Roshita A, Fahmida U. Psychosocial care and nutritional status of children aged 6-36 months among patrilineal (Karo) and matrilineal (Minangkabau) Households in Jakarta. Asia Pacific Journal Clinic Nutrition. 2007;16(2): 293-300.

15. Adisasmito W. Sistem kesehatan. Jakarta: PT Raja Grafindo Persada; 2007.

16. Departemen Gizi dan Kesehatan Masyarakat FKM UI. Gizi dan kesehatan masyarakat. Jakarta: PT Raja Grafindo Persada; 2007.

17. Engle PL, Bentley M, Pelto G. The Role of Care in Nutrition Programmers: Current Research and a Research Ganda. Proceedings of The Nutrition Society. 2000;59:25-35.

18. Nti CA, Lartey A. Influence of care practices on nutritional status of Ghanaian children. Nutrition Research and Practice. 2008;2(2):93-9.

19. Lubis R. Hubungan pola asuh dengan status gizi anak balita di wilayah kerja Puskesmas Pantai Cermin Kecamatan Tanjung Pura Kabupaten Langkat Tahun 2008 (skripsi). Medan: Fakultas Kesehatan Masyarakat Universitas Sumatera Utara; 2008.

20. Yulia C, Sunarti E, Roosita K. Pola asuh makan dan kesehatan anak balita pada keluarga wanita pemetik teh di PTPN VII Pangalengan (tesis). Bogor: Institut Pertanian Bogor; 2008. 